\title{
Catalytic Autoxidation of Fatty Acid Methyl Esters from Jatropha Oil
}

\author{
Abebe K. Endalew and Yohannes Kiros \\ Department of Chemical Engineering \& Technology, KTH Royal Institute of Technology, 10044 Stockholm, Sweden \\ Correspondence should be addressed to Yohannes Kiros; yohannes@kth.se
}

Received 10 June 2014; Accepted 1 October 2014; Published 16 October 2014

Academic Editor: Marten Ternan

Copyright (C) 2014 A. K. Endalew and Y. Kiros. This is an open access article distributed under the Creative Commons Attribution License, which permits unrestricted use, distribution, and reproduction in any medium, provided the original work is properly cited.

Metal catalysts for transesterification of vegetable oils can cause autoxidation side reactions which reduces the fuel quality of the biodiesel. On the other side, oxidation of highly unsaturated oils can open opportunities for the synthesis of other important renewable chemical products. This study reports catalytic oxidation of fatty acids of Jatropha curcas oil (JCO) by $\mathrm{Li}-\mathrm{CaO} / \mathrm{Fe}_{2}(\mathrm{SO})_{3}$ catalyst during transesterification at mild reaction conditions. The catalytic oxidation of the triglycerides was shown to be enhanced by the presence of lithium incorporated in the otherwise active catalyst combination of $\mathrm{CaO} / \mathrm{Fe}_{2}\left(\mathrm{SO}_{4}\right)_{3}$ used for high conversion into FAME. Matrix-assisted laser desorption/ionization time-of-flight mass spectrometry (MALDI-TOF MS) was used to assess the reaction products.

\section{Introduction}

Biodiesel is a renewable fuel which has similar energy density and physical properties with conventional diesel fuel. Transesterification is the most applied chemical method for biodiesel production from vegetable and nonedible oils. This chemical process proceeds in the presence of either homogeneous or heterogeneous catalysts. Biodiesel can replace the conventional fossil diesel fuel when its specifications on oxidative stability fulfill the European Standard EN 14214 or the American Standard ASTM D6751 $[1,2]$. However, there are chemical processes which affect the quality of biodiesel during transesterification process or storage. One of the main causes of loss of quality is autoxidation. Due to the high unsaturated composition of vegetable oils and their derivatives, oxidation is a common phenomenon. Autoxidation of unsaturated oil and fatty acid methyl esters is a chemical reaction which can be initiated by thermolysis at elevated temperature, by the presence of metal catalysts or impurities, by hydrolysis in the presence of humid medium, or photolysis due to exposure to light [3-5]. Autoxidation proceeds by radical mechanism in the presence of molecular oxygen as oxidant. Although autoxidation usually has an induction time and is dependent on the structure of the saturated or unsaturated fatty acid of the feedstock and final product, the initial oxidation step is believed to proceed through hydroperoxide formation resulting in the creation of compounds such as acids and aldehydes or further reaction with another group of fatty acids to form dimers $[2,6-8]$.

Catalytic autoxidation has been used in many organic reactions and transition metal catalysts are frequently mentioned as the type of heterogeneous catalysts in the process $[9,10]$. Furthermore, promoted or unpromoted alkali or alkali rare earth metal oxide base catalysts have been known for catalytic oxidative coupling to higher hydrocarbons, proceeding through radical chemistry $[11,12]$. Due to the high basic surface of the alkali or alkali doped alkaline earth metal oxide, abstraction of hydrogen from the allylic or bis-allylic position of unsaturated carbon chain is possible producing radicals for the autoxidation initiation. The possible oxidation reaction mechanisms for the fatty acid methyl ester (FAME) with molecular oxygen have been discussed in the literature $[13,14]$. Although the autoxidation process is a complex process, it is believed to have three main steps, that is, initiation, propagation, and termination. The initiation step occurs by abstraction of hydrogen from the fatty acid methyl ester on the catalyst surface. The peroxide formed during the propagation step is unstable and spontaneously goes to 
TABLE 1: Physical properties of Jatropha curcas biodiesel.

\begin{tabular}{lll}
\hline $\begin{array}{l}\text { Physical } \\
\text { properties }\end{array}$ & $\begin{array}{l}\mathrm{CaO} / \mathrm{Fe}_{2}\left(\mathrm{SO}_{4}\right)_{3} \\
\text { product }(\mathrm{A})\end{array}$ & $\begin{array}{l}\mathrm{Li}-\mathrm{CaO} / \mathrm{Fe}_{2}\left(\mathrm{SO}_{4}\right)_{3} \\
\text { product }(\mathrm{B})\end{array}$ \\
\hline $\begin{array}{l}\text { Density }\left[\mathrm{g} / \mathrm{cm}^{3}\right] \\
\text { Viscosity }[\mathrm{cSt}]\end{array}$ & 0.88 & 0.905 \\
Color & 4.3 & 5.8 \\
& Yellow & $\begin{array}{l}\text { Dark brown } \\
\text { Very low solubility in } \\
\text { heptane }\end{array}$ \\
Solubility & $\begin{array}{l}\text { Soluble in heptane, } \\
\text { diethyl ether, toluene, } \\
\text { and chloroform }\end{array}$ & $\begin{array}{l}\text { Partially soluble in } \\
\text { diethyl ether, } \\
\text { chloroform, and } \\
\text { toluene }\end{array}$ \\
\hline
\end{tabular}

the termination step, where epoxies, hydroperoxides, acids, alcohols, ketones, or aldehydes are considered to be the final compounds.

Oxidation increases the oxygen content and reduces the quality and the energy density of biodiesel. On the other hand, oxidation of FAME can open opportunities for the synthesis of important renewable bulk or fine chemical products such as lubricants, surfactants, pharmaceutical products, and other value-added chemical products [15-17]. As the total composition of oleic, linoleic, and linolenic acids related to the number of double bonds in jatropha oil is more than $75 \%$ [18], oxidation is believed to take place at increased rate compared to other oils that have less unsaturated compounds. As to our knowledge, autoxidation of these fatty acid compounds using alkali doped metal oxide catalysts has not been reported. The aim of this study is to investigate autoxidation of Jatropha curcas oil by $\mathrm{Li}-\mathrm{CaO}$ catalyst at mild reaction conditions and elucidate the reaction products by MALDITOF mass spectrometry.

\section{Materials and Methods}

2.1. Materials. Crude Jatropha curcas oil (JCO) was obtained from Tamil Nadu Agricultural University (TNAU), Coimbatore, India. Rapeseed oil (RSO) was purchased commercially. $\mathrm{CaCO}_{3}$ (99.9\% purity), $\mathrm{LiNO}_{3}$ (99.9\% purity), and methanol (extra pure) were obtained from MERCK. Anhydrous $\mathrm{Fe}_{2}\left(\mathrm{SO}_{4}\right)_{3}$ was obtained from VWR Prolabo; propyl acetate and a standard fatty acid methyl ester (FAME) $\mathrm{C}_{8}-\mathrm{C}_{24}$ for GC calibration were also purchased from Sigma-Aldrich.

2.2. Catalyst Preparation. Calcium oxide $(\mathrm{CaO})$ was prepared by decomposing pulverized $\mathrm{CaCO}_{3}$ at $960^{\circ} \mathrm{C}$ for three and half hours. Lithium doped calcium oxide ( $\mathrm{Li}-\mathrm{CaO})$ was prepared by incipient wetness impregnation method [19]. The solution was dried in oven at $120^{\circ} \mathrm{C}$ for $3 \mathrm{hrs}$ and was calcinated at $550^{\circ} \mathrm{C}$ for $3 \mathrm{hrs}$. Anhydrous iron(III) sulfate $\left(\mathrm{Fe}_{2}\left(\mathrm{SO}_{4}\right)_{3}\right)$ was dried at $110^{\circ} \mathrm{C}$ for $3 \mathrm{hrs}$ prior to use in order to remove any moisture content due to exposal to air.

2.3. Experimental. A three-necked glass reactor immersed in a thermostat hot bath system was used to carry out the catalytic oxidation process. Experiments were performed under reaction conditions of $60^{\circ} \mathrm{C}$, 3-hour reaction time, $6: 1 \mathrm{~mol}$ of alcohol to oil ratio, 5 wt.\% catalyst (based on weight of oil), and agitation speed of $300 \mathrm{rpm}$. A mixture of catalyst and methanol was initially stirred and heated to the reaction temperature. $90 \mathrm{~mL}$ of oil was heated separately to reach the reaction temperature. Oil and catalyst-methanol mixture were mixed in the reactor. Cooling was done by circulating water through a condenser. Thermometers were used to measure both the reaction and water bath temperatures. Reaction agitation was made by Teflon stirrer driven by an electric motor. The reactor was unsealed and atmospheric air/oxygen can easily enter the reaction mixtures. Centrifugation of the reaction products was done at $5700 \mathrm{rpm}$ for 30 minutes whereas a clear phase separation was achieved. After centrifugation, the phases were obtained in the following order from top to bottom: methanol, FAME/oxidized FAME, glycerol, and solid catalyst, respectively. Samples for further analysis were prepared from the part of the clear FAME/oxidized FAME.

2.4. Quantitative and Qualitative Tests. Agilent gas chromatography (GC) 6890 with split inlet and flame ionization detector (FID) was used for quantitative analysis of the samples. Propyl acetate was used as the GC internal standard. The GC was calibrated for methyl ester of carbon numbers ranging from $\mathrm{C}_{8}$ to $\mathrm{C}_{24}$. Matrix-assisted laser desorption/ionization time-of-flight mass spectrometry (MALDI-TOF MS) was used for qualitative study of the samples. Bruker UltraFlex MALDI-TOF mass spectroscopy with nitrogen laser and ion source with reflector was used for sample analysis. Samples were dissolved in chloroform for analysis. Concentrations of $20 \mathrm{mg} / \mathrm{mL}$ were prepared and used in the analysis. 2,5-Dihydroxybenzoic acid (DHB) matrix solution was prepared with a concentration of $10 \mathrm{mg} / \mathrm{mL}$ in tetrahydrofuran (THF) solvent. Sodium (Na) salt adduct was used. $10 \mu \mathrm{L}$ of sample solution and $5 \mu \mathrm{L}$ of DHB matrix solution with salt were mixed and vortexed. About $1 \mu \mathrm{L}$ of the vortexed mixture was spotted on the target plate and the spot was allowed to dry at ambient temperature. Spectra were obtained and processed using FlexAnalysis software.

\section{Result and Discussion}

3.1. Physical Properties. In order to protect soap formation due to the high free fatty acid content of jatropha oil during the reaction, mixtures of $\mathrm{Fe}_{2}\left(\mathrm{SO}_{4}\right)_{3}$ with $\mathrm{CaO}$ or $\mathrm{Li}$ - $\mathrm{CaO}$ were used for simultaneous transesterification and esterification reported in [19]. FAME produced by $\mathrm{CaO} / \mathrm{Fe}_{2}\left(\mathrm{SO}_{4}\right)_{3}$ and $\mathrm{Li}-\mathrm{CaO} / \mathrm{Fe}_{2}\left(\mathrm{SO}_{4}\right)_{3}$ catalysts were found to have different properties as shown in Table 1 with higher density and viscosity for the latter. Likewise the visual differences in color of the products and their solubility in various media differ significantly. Figure 1 shows the different colors of the biodiesel produced by the two catalysts from JCO and rapeseed oil (RSO). Rapeseed biodiesel obtained by $\mathrm{CaO}$ has light yellow color (Figure 1 (1)) while Li-CaO catalyst gave greenish color (Figure 1 (3)). This study has focused on the type of products obtained from JCO with further qualitative analysis. The acid-base titration method gave distinctively higher concentrations of FFA, that is, 9 wt.\% FFA 


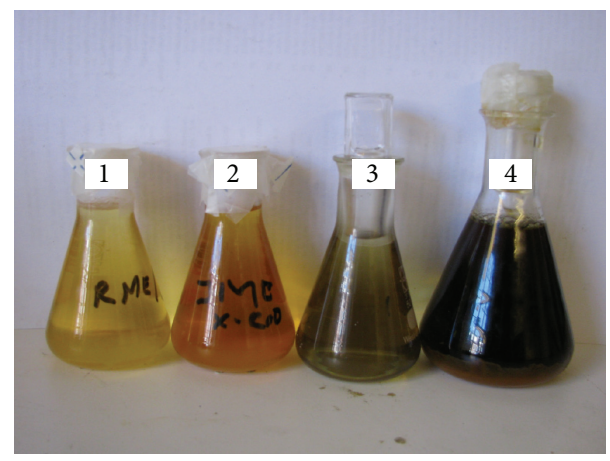

FIGURE 1: Colors of biodiesel produced (1) RSO by CaO catalyst, (2) JCO biodiesel by $\mathrm{CaO} / \mathrm{Fe}_{2}\left(\mathrm{SO}_{4}\right)_{3}$ catalyst, (3) $\mathrm{RSO}$ by $\mathrm{Li}-\mathrm{CaO}$ catalyst, and (4) JCO biodiesel by $\mathrm{Li}-\mathrm{CaO} / \mathrm{Fe}_{2}\left(\mathrm{SO}_{4}\right)_{3}$ catalyst.

for jatropha oil compared with $0.53 \mathrm{wt} . \%$ for rapeseed oil [19]. The presence of FFA would obviously lead to lower oil stability index (OSI) promoting oxidation [20].

3.2. MALDI-TOF MS Analysis. The two products from JCO by $\mathrm{Li}-\mathrm{CaO} / \mathrm{Fe}_{2}\left(\mathrm{SO}_{4}\right)_{3}$ and $\mathrm{CaO} / \mathrm{Fe}_{2}\left(\mathrm{SO}_{4}\right)_{3}$ showed two different physical properties as shown in Table 1. In order to get structural information a mass spectrometer was used for qualitative analysis of the final products. Two samples were prepared for MALDI-TOF MS analysis named as sample A, obtained by $\mathrm{CaO} / \mathrm{Fe}_{2}\left(\mathrm{SO}_{4}\right)_{3}$ catalyst, and sample $\mathrm{B}$, obtained by $\mathrm{Li}-\mathrm{CaO} / \mathrm{Fe}_{2}\left(\mathrm{SO}_{4}\right)_{3}$ catalyst. MALDI-TOF MS is an ionization technique coupled with high resolution analyzers, where the mass spectra are recorded as signal and as a function of time and have found applications in small and large molecules, such as proteins, peptides, and polymers. Among its key advantages are determination of molecular weights, chemical structure, simple operation and fast response, and high accuracy and peak separation.

Biodiesel produced from vegetable/nonedible oils has varying composition and structure. Identifying and studying these compositions is crucial in determining the quality of biodiesel. This type of study can also give information about side reactions and unreacted species during the transesterification using homogeneous or heterogeneous catalysis. Hitherto, analysis of reaction products using MALDI-TOF MS has not yet been done to understand the various compounds, emanating from such reactions. Alkali $\left(\mathrm{Li}^{+}, \mathrm{Na}^{+}\right.$, and $\left.\mathrm{K}^{+}\right)$and transition $\left(\mathrm{Cu}^{+}, \mathrm{Ag}^{+}\right)$metal salts are commonly used as cations for matrix solution preparation. Alkali metal salts are found to be the best cations for esters [21] and in our case $\mathrm{Na}^{+}$adduct was used for the analysis. The matrix dihydroxybenzoic acid (DHB) is the most common type of matrices used in MALDI-TOF MS analysis of lipids as well as esters.

3.3. Quantification of the Spectra. Biodiesel has a complex structure and identifying all the spectra of the components is challenging. The presence of fragment ions produced during ionization process also makes the peak identification be more difficult. As shown in Figure 2, mass spectra of biodiesel have three main regions: methyl esters and monoglycerides (region 1), diglycerides (region 2), and triglycerides (region 3 ). The MALDI-TOF MS spectra of triglycerides and diglycerides in heated vegetable oils were reported in [22-26]. This work focuses on the oxidation of FAME and FAME products with spectral identification as depicted in the magnification part of the $m / z$ in the respective areas of (a), (b), and (c), respectively.

Fragments of methyl esters and glycerides can be produced during ionization process by loss of some part of the carboxylic group such as $\left(-\mathrm{OCH}_{3}\right)$ and $-\mathrm{CH}_{3}$ [27]. These fragment ions can appear in the spectra either as anion or with sodium adducts. Figure 2 shows spectra of biodiesel produced by $\mathrm{CaO} / \mathrm{Fe}_{2}\left(\mathrm{SO}_{4}\right)_{3}$ catalysts. In this figure, loss of $-\mathrm{OCH}_{3}$ of methyl palmitate during ionization gives peak of $m / z=239$. Loss of the same group from methyl linolineate and methyl linoleate esters gives peaks of $m / z=$ 261 and 263, respectively (peak numbers are not shown). Deuteration of saturated methyl ester was noticed. Deuterated methyl palmitate ion appeared at a peak of $\mathrm{m} / z=$ 272.

Methyl palmitate, methyl linolineate, methyl linoleate, and methyl oleate are major methyl esters in jatropha biodiesel. Major methyl ester peaks appeared in their respective $m / z$. Methyl palmitate with sodium adduct $\left[\mathrm{M}+\mathrm{Na}^{+}\right]$ gives $m / z=293$. Methyl linolineate $(m / z=315)$, methyl linoleate $(m / z=317)$, methyl oleate $(m / z=319)$, and methyl stearate $(m / z=321)$ peaks were noticed. Monoglyceride spectra appeared up to $m / z=430$. The mass spectra of biodiesel obtained by $\mathrm{CaO} / \mathrm{Fe}_{2}\left(\mathrm{SO}_{4}\right)_{3}$ were also compared with commercially available biodiesel and similar spectra peaks were found. The spectra of the biodiesel thus show a normal performance and characteristics compared to those of other FAME products.

Figure 3 shows the mass spectra of jatropha biodiesel produced by $\mathrm{Li}-\mathrm{CaO} / \mathrm{Fe}_{2}\left(\mathrm{SO}_{4}\right)_{3}$ catalyst. Spectra of biodiesel produced by this catalyst showed different spectra than biodiesel produced by $\mathrm{CaO} / \mathrm{Fe}_{2}\left(\mathrm{SO}_{4}\right)_{3}$. More unsaturated methyl esters disappeared and other new spectra appeared. Methyl palmitate, methyl oleate, and methyl stearate appeared at $\mathrm{m} / z=$ $293, m / z=319$, and $m / z=321$, respectively. All other methyl esters between $\mathrm{m} / z=293$ and $\mathrm{m} / z=321$ were converted to other products. Epoxies and hydroxyls of methyl linolineate, methyl linoleate, and methyl oleate appeared at $m / z=331, m / z=333$, and $m / z=335$, respectively. Peaks of ketones from linoleate and oleate did coincide with their respective epoxies. Free fatty acid of oleic and linoleic with sodium adduct came at $m / z=305$ and $m / z=303$, respectively. New peaks of $m / z=413$ and $m / z=429$ did also emerge. This is due to further oxidation of the more unsaturated fatty acids. Hydroperoxides of methyl oleate were noticed at $m / z=351$ and $m / z=383$ while $m / z=349$, $m / z=381$, and $m / z=413$ were hydroperoxides of methyl linoleate. Hydroperoxides of methyl linoleate with hydroxyl was also visible at $m / z=429$. Hydroperoxides for methyl linolineate emerged at $m / z=347$ and 379. The interesting phenomenon is the disappearance of more unsaturated methyl esters and the appearance of new peaks which is caused by the catalytic autoxidation of $\mathrm{Li}-\mathrm{CaO} / \mathrm{Fe}_{2}\left(\mathrm{SO}_{4}\right)_{3}$ catalyst. 

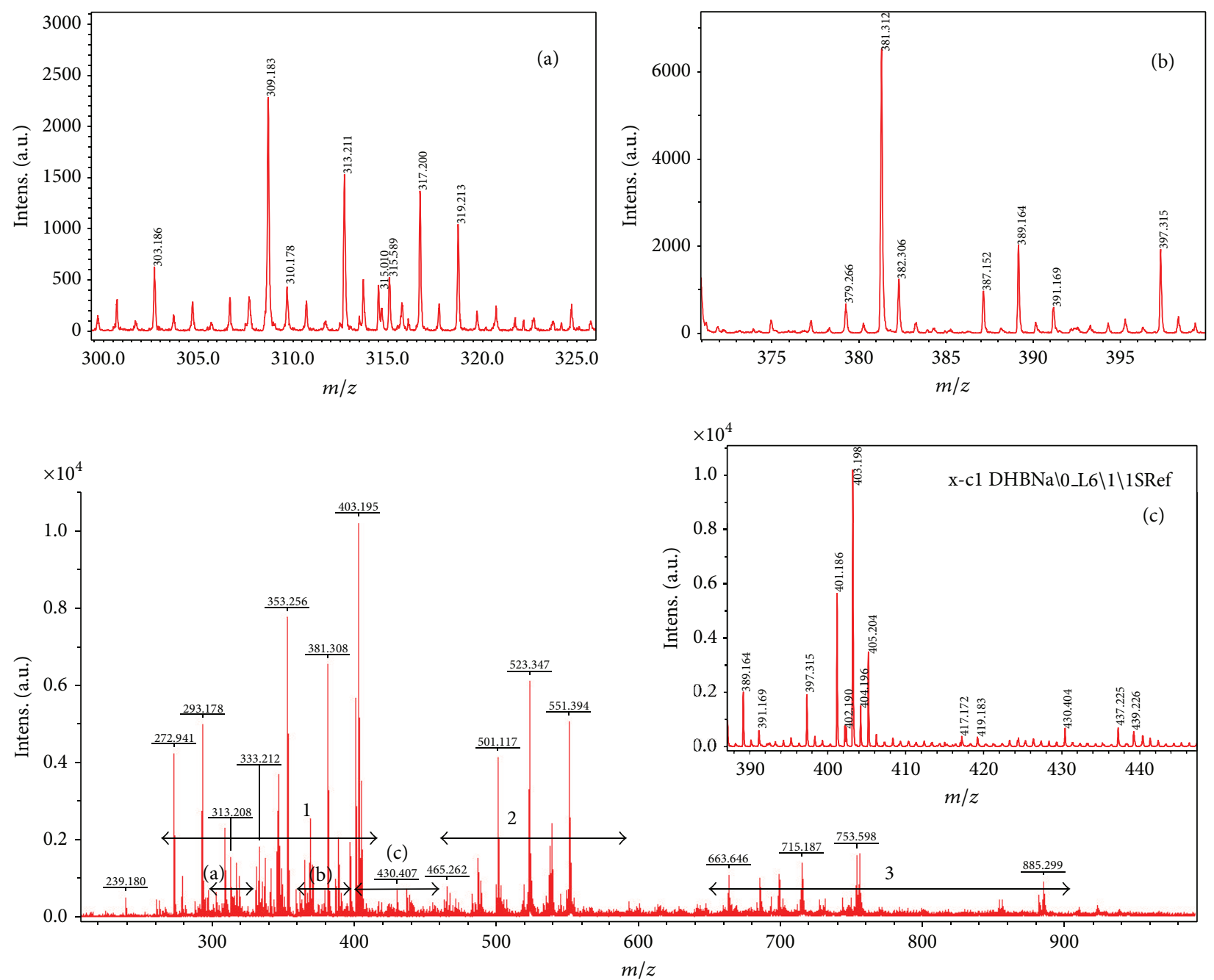

Figure 2: MALDI-TOF MS spectra of sample A $\left(\mathrm{CaO} / \mathrm{Fe}_{2}\left(\mathrm{SO}_{4}\right)_{3}\right)$. Regions (1): FAME and monoglycerides, (2): diglycerides, and (3): triglycerides ((a), (b), and (c) magnification of $m / z$ in the respective area).

3.4. Oxidation of FAME. The difference in the physical properties and MALDI-TOF MS characterization in the final products is due to the oxidation of the components. As $\mathrm{Fe}_{2}\left(\mathrm{SO}_{4}\right)_{3}$ is only used for esterification reaction [19], the difference is attributed to the presence of either $\mathrm{Li}-\mathrm{CaO}$ or $\mathrm{CaO}$ catalyst and hence the combination of $\mathrm{Li}-\mathrm{CaO} / \mathrm{Fe}_{2}\left(\mathrm{SO}_{4}\right)_{3}$ or $\mathrm{CaO} / \mathrm{Fe}_{2}\left(\mathrm{SO}_{4}\right)_{3}$. The kinetics for the autoxidation of FAMEs depends on the degree of unsaturation. Polyunsaturated fatty acid methyl esters such as linoleate and linolineate can easily oxidize at low temperature [13]. Monounsaturated FAMEs such as methyl oleate have low oxidizability compared to polyunsaturated FAMEs [28]. This supports the presence of unoxidized methyl oleate and palmitate in $\mathrm{Li}-\mathrm{CaO} / \mathrm{Fe}_{2}\left(\mathrm{SO}_{4}\right)_{3}$ catalyst product. Hydroperoxides are known to be the main products of autoxidation of unsaturated FAME and are stable at low temperature $[9,28,29]$. Similarly, GC analysis of oxidized product showed that low carbon numbers of oxidized products were not observed and the main products of oxidation are hydroperoxides of FAME. The detector of
GC responds to the number of carbons in organic molecules and it was difficult to see new peaks of methyl esters with hydroperoxides; instead they appeared with similar retention time as the parent methyl ester. However, further quantification of these different yields of products is still required.

As shown in Figure 1, the dark brown color for $\mathrm{Li}-\mathrm{CaO} / \mathrm{Fe}_{2}\left(\mathrm{SO}_{4}\right)_{3}$ catalyst products is ascribed to high oxidation rates of the reaction. Due to the presence of high oxygen containing products, the viscosity and density were found to be higher than the product obtained by $\mathrm{CaO} / \mathrm{Fe}_{2}\left(\mathrm{SO}_{4}\right)_{3}$. Although it is a complex process to point out each of the peaks in the mass spectroscopy, it is clearly shown that the oxidation of unsaturated fatty acids takes place in the presence of $\mathrm{Li}-\mathrm{CaO} / \mathrm{Fe}_{2}\left(\mathrm{SO}_{4}\right)_{3}$ catalyst. This study shows a new way of catalytic reaction for autoxidation of jatropha oil for synthesis of other chemical products. The oxidized biodiesel does have a viscosity in the range of ASTM D6751 (ca.1.9-6 cSt). However, the calorific value may be less than that of the normal biodiesel. Further studies 

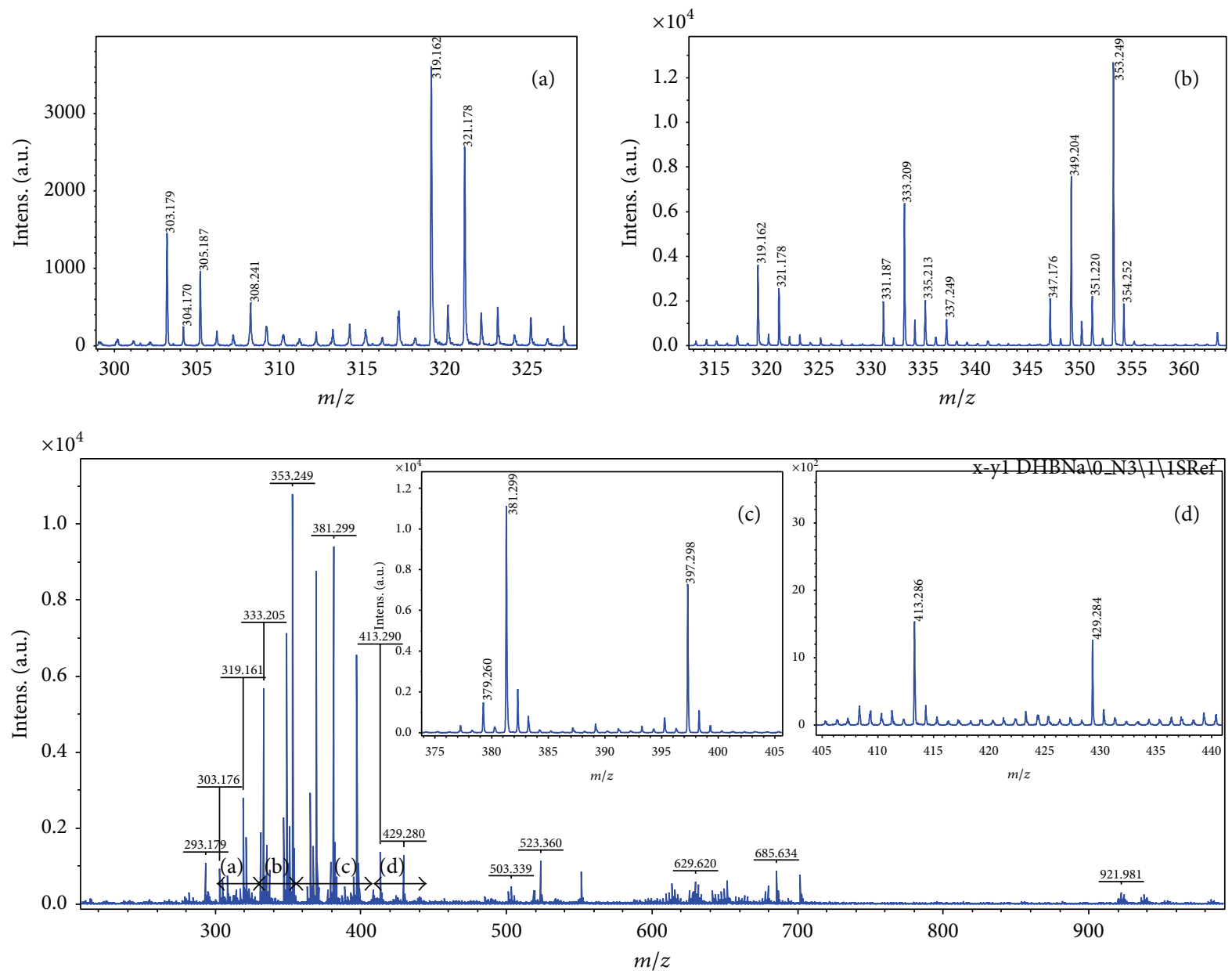

Figure 3: MALDI-TOF MS spectra for sample B ( $\mathrm{Li}-\mathrm{CaO} / \mathrm{Fe}_{2}\left(\mathrm{SO}_{4}\right)_{3}$ catalyst); (a), (b), (c), and (d) are magnification in the respective $m / z$ area.

concerning cetane number, cloud point, acidity, and stability are necessary to substantiate additional information on the properties of the products.

\section{Conclusion}

Catalytic autoxidation of biodiesel constitutes loss of fuel quality. On the other side, oxidation of biodiesel can open an opportunity for synthesis of other renewable chemical products. $\mathrm{Li}-\mathrm{CaO} / \mathrm{Fe}_{2}\left(\mathrm{SO}_{4}\right)_{3}$ catalyst was found to be active for transesterification of vegetable oils such as rapeseed oil into biodiesel while oil from jatropha containing highly unsaturated fatty acids was converted to oxidized components. $\mathrm{Li}-\mathrm{CaO} / \mathrm{Fe}_{2}\left(\mathrm{SO}_{4}\right)_{3}$ is active for the autoxidation reaction of jatropha oil compared to $\mathrm{CaO} / \mathrm{Fe}_{2}\left(\mathrm{SO}_{4}\right)_{3}$. Qualitative study using MALDI-TOF mass spectroscopy analysis showed that the unsaturated methyl esters were oxidized and were found together with FAME products.

\section{Conflict of Interests}

The authors declare that there is no conflict of interests regarding the publication of this paper.

\section{Acknowledgments}

The Department of Chemical Engineering and Technology, $\mathrm{KTH}$, is acknowledged for creating the opportunity for Mr. Abebe K. Endalew to work on this research activity. Special thanks are due to Peter Kaali at the Department of Fiber and Polymer Technology for his valuable help in the MALDI-TOF MS.

\section{References}

[1] P. Heinrich, "High biodiesel quality required by European Standards," European Journal of Lipid Science and Technology, vol. 104, pp. 371-375, 2002.

[2] G. Knothe, "Some aspects of biodiesel oxidative stability," Fuel Processing Technology, vol. 88, no. 7, pp. 669-677, 2007.

[3] E. N. Frankel, "Lipid oxidation," Progress in Lipid Research, vol. 19, no. 1-2, pp. 1-22, 1980.

[4] J. Kanner and I. Rosenthal, "An assessment of lipid oxidation in foods," Pure \& Applied Chemistry, vol. 64, no. 12, pp. 1959-1964, 1992.

[5] J. Paligová, L. Jorívá, and J. Cvengroš, "Study of FAME stability," Energy and Fuels, vol. 22, no. 3, pp. 1991-1996, 2008. 
[6] G. Karavalakis, S. Stournas, and D. Karonis, "Evaluation of the oxidation stability of diesel/biodiesel blends," Fuel, vol. 89, no. 9, pp. 2483-2489, 2010.

[7] L. M. Das, D. K. Bora, S. Pradhan, M. K. Naik, and S. N. Naik, "Long-term storage stability of biodiesel produced from Karanja oil," Fuel, vol. 88, no. 11, pp. 2315-2318, 2009.

[8] R. L. McCormick, M. Ratcliff, L. Moens, and R. Lawrence, "Several factors affecting the stability of biodiesel in standard accelerated tests," Fuel Processing Technology, vol. 88, no. 7, pp. 651-657, 2007.

[9] I. Hermans, J. Peeters, and P. A. Jacobs, "Autoxidation of hydrocarbons: from chemistry to catalysis," Topics in Catalysis, vol. 50, no. 1-4, pp. 124-132, 2008.

[10] I. Hermans, J. Peeters, and P. A. Jacobs, "Autoxidation chemistry: bridging the gap between homogeneous radical chemistry and (heterogeneous) catalysis," Topics in Catalysis, vol. 48, no. 14, pp. 41-48, 2008.

[11] J. H. Lunsford, "The catalytic conversion of methane to higher hydrocarbons," Catalysis Today, vol. 6, no. 3, pp. 235-259, 1990.

[12] J. M. Deboy and R. F. Hicks, "The oxidative coupling of methane over alkali, alkaline earth, and rare earth oxides," Industrial and Engineering Chemistry Research®, vol. 27, no. 9, pp. 1577-1582, 1988.

[13] R. Kumarathasan, A. B. Rajkumar, N. R. Hunter, and H. D. Gesser, "Autoxidation and yellowing of methyl linolenate," Progress in Lipid Research, vol. 31, no. 2, pp. 109-126, 1992.

[14] R. A. Hancock, N. J. Leeves, and P. F. Nicks, "Studies in autoxidation. Part I. The volatile by-products resulting from the autoxidation of unsaturated fatty acid methyl esters," Progress in Organic Coatings, vol. 17, no. 3, pp. 321-336, 1989.

[15] A. Behr and J. P. Gomes, "The refinement of renewable resources: new important derivatives of fatty acids and glycerol," European Journal of Lipid Science and Technology, vol. 112, no. 1, pp. 31-50, 2010.

[16] M. J. Climent, A. Corma, S. B. A. Hamid, S. Iborra, and M. Mifsud, "Chemicals from biomass derived products: synthesis of polyoxyethyleneglycol esters from fatty acid methyl esters with solid basic catalysts," Green Chemistry, vol. 8, no. 6, pp. 524-532, 2006.

[17] M. A. R. Meier, J. O. Metzger, and U. S. Schubert, "Plant oil renewable resources as green alternatives in polymer science," Chemical Society Reviews, vol. 36, no. 11, pp. 1788-1802, 2007.

[18] G. M. Gübitz, M. Mittelbach, and M. Trabi, "Exploitation of the tropical oil seed plant Jatropha curcas L," Bioresource Technology, vol. 67, no. 1, pp. 73-82, 1999.

[19] A. K. Endalew, Y. Kiros, and R. Zanzi, "Heterogeneous catalysis for biodiesel production from Jatropha curcas oil (JCO)," Energy, vol. 36, no. 5, pp. 2693-2700, 2011.

[20] G. Knothe and R. O. Dunn, "Dependence of oil stability index of fatty compounds on their structure and concentration and presence of metals," Journal of the American Oil Chemists' Society, vol. 80, no. 10, pp. 1021-1026, 2003.

[21] V. Vrkoslav, R. Míková, and J. Cvačka, "Characterization of natural wax esters by MALDI-TOF mass spectrometry," Journal of Mass Spectrometry, vol. 44, no. 1, pp. 101-110, 2009.

[22] G. Picariello, A. Paduano, R. Sacchi, and F. Addeo, "MALDITOF mass spectrometry profiling of polar and nonpolar fractions in heated vegetable oils," Journal of Agricultural and Food Chemistry, vol. 57, no. 12, pp. 5391-5400, 2009.
[23] J. Schiller, R. Süß, M. Petković, and K. Arnold, “Thermal stressing of unsaturated vegetable oils: effects analysed by MALDITOF mass spectrometry, ${ }^{1} \mathrm{H}$ and ${ }^{31} \mathrm{P}$ NMR spectroscopy," European Food Research and Technology, vol. 215, no. 4, pp. 282-286, 2002.

[24] C. D. Calvano, A. Aresta, F. Palmisano, and C. G. Zambonin, "A laser desorption ionization time-of-flight mass spectrometry investigation into triacylglycerols oxidation during thermal stressing of edible oils," Analytical and Bioanalytical Chemistry, vol. 389, no. 7-8, pp. 2075-2084, 2007.

[25] B. Fuchs and J. Schiller, "Application of MALDI-TOF mass spectrometry in lipidomics," European Journal of Lipid Science and Technology, vol. 111, no. 1, pp. 83-98, 2009.

[26] K. A. Al-Saad, V. Zabrouskov, W. F. Siems, N. R. Knowles, R. M. Hannan, and H. H. Hill Jr., "Matrix-assisted laser desorption/ionization time-of-flight mass spectrometry of lipids: ionization and prompt fragmentation patterns," Rapid Communications in Mass Spectrometry, vol. 17, no. 1, pp. 87-96, 2003.

[27] W. W. Christie, "Mass spectra of methyl esters of fatty acids," Scottish Crop Research Institute (and Mylnefield Lipid Analysis), Invergowrie, Dundee (DD2 5DA), Scotland, http://lipidlibrary.aocs.org/.

[28] A. Morales, C. Dobarganes, G. Márquez-Ruiz, and J. Velasco, "Quantitation of hydroperoxy-, keto- and hydroxy-dienes during oxidation of FAMEs from high-linoleic and high-oleic sunflower oils," JAOCS, Journal of the American Oil Chemists' Society, vol. 87, no. 11, pp. 1271-1279, 2010.

[29] H. W. Gardner, "Oxygen radical chemistry of polyunsaturated fatty acids," Free Radical Biology and Medicine, vol. 7, no. 1, pp. 65-86, 1989. 


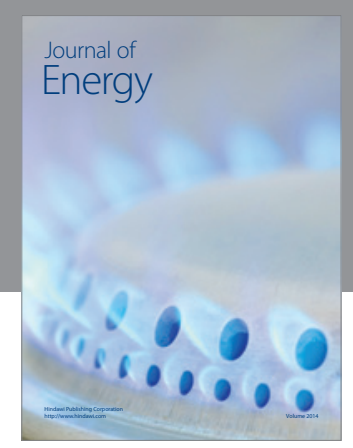

Journal of

Industrial Engineering
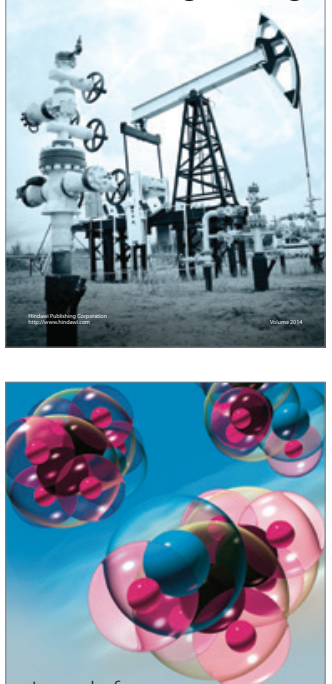

Fuels
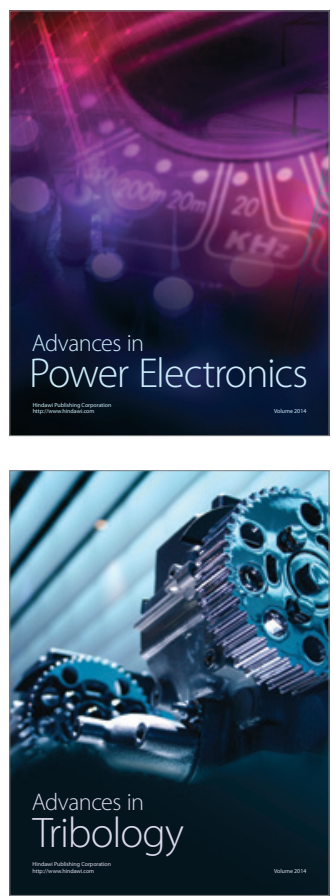

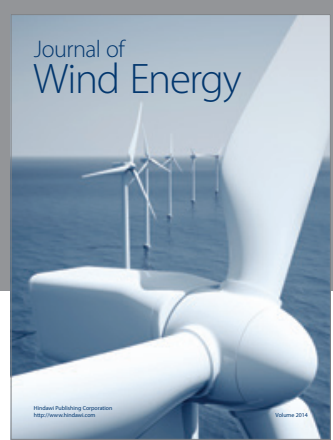

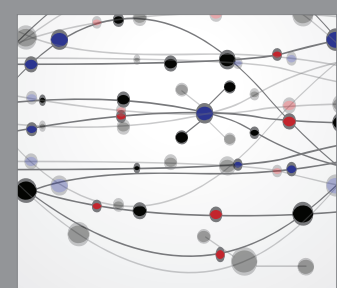

The Scientific World Journal

Submit your manuscripts at http://www.hindawi.com

Journal of

Structures
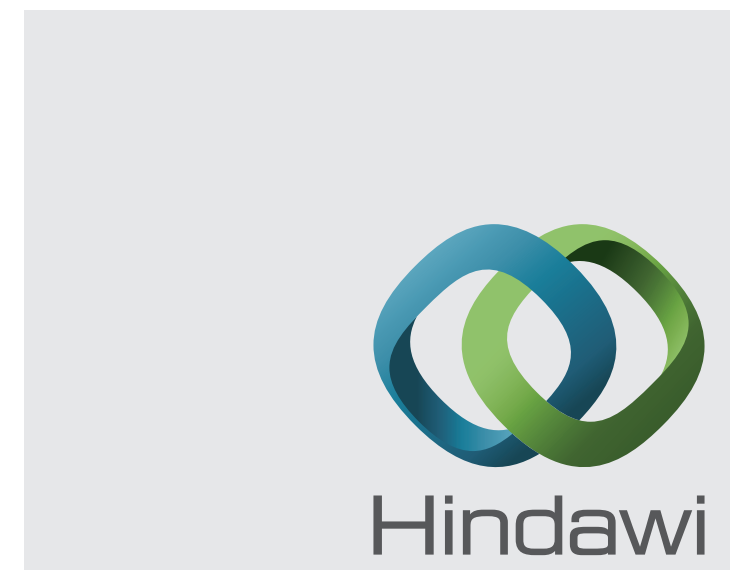

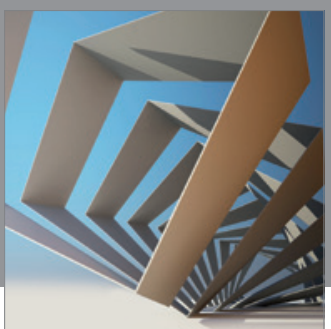

Rotating

Machinery
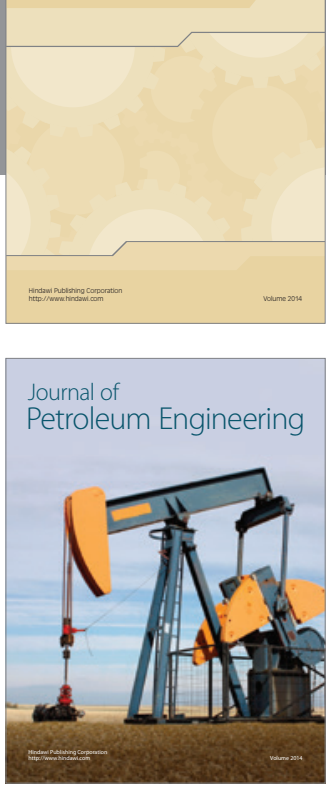

Journal of

Solar Energy
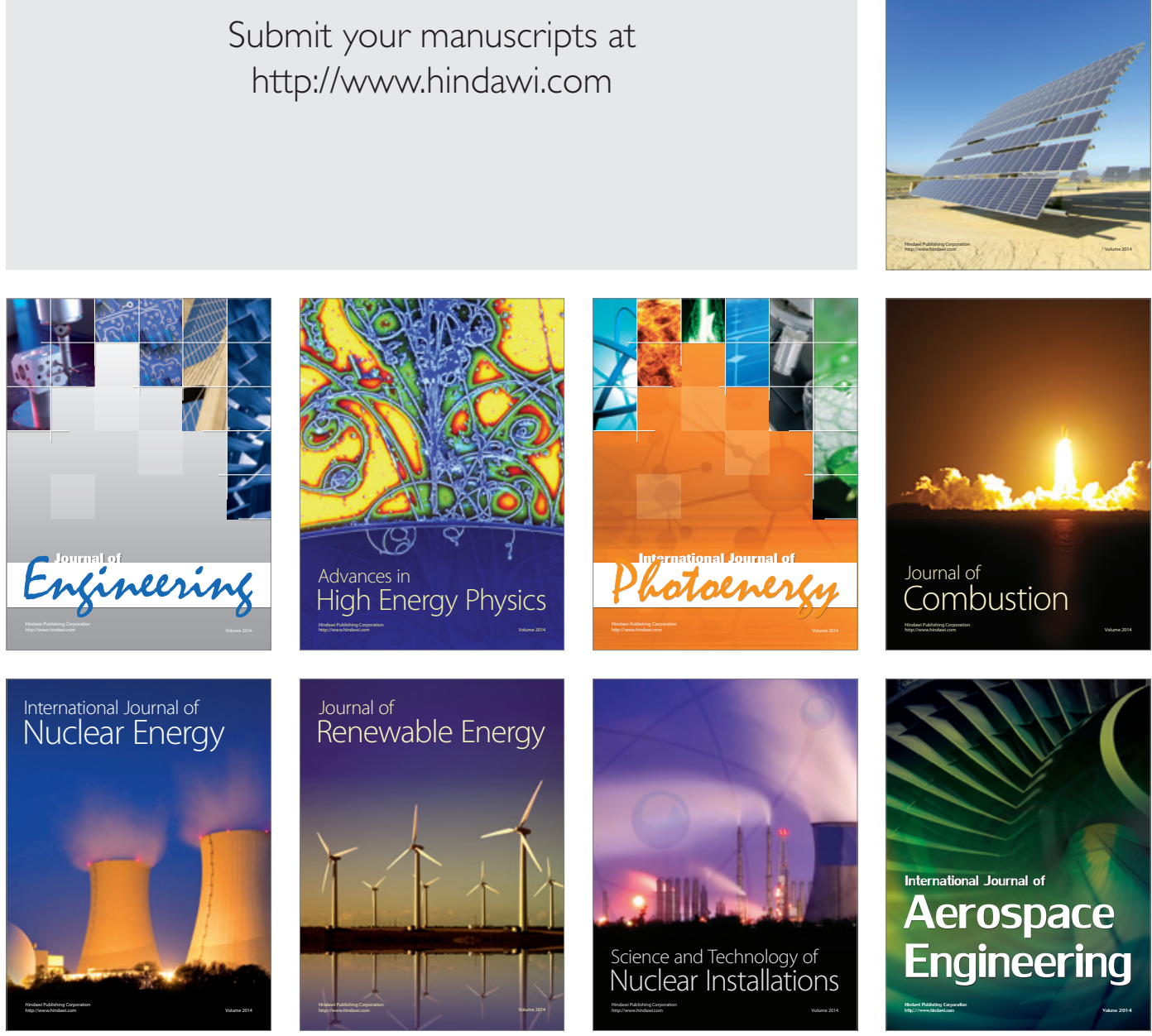